\title{
Habitat fragmentation and the future structure of tree assemblages in a fragmented Atlantic forest landscape
}

\author{
Edgar E. Santo-Silva ${ }^{1}$, Wanessa R. Almeida ${ }^{1}$, Marcelo Tabarelli ${ }^{1} \&$ Carlos \\ A. Peres ${ }^{2}$ \\ ${ }^{1}$ Federal University of Pernambuco, Department of Botany, Av. Prof. Moraes Rego, \\ S/N, Cidade Universitária, 50670-901, Recife-PE, Brasil. \\ ${ }^{2}$ School of Environmental Sciences, University of East Anglia, Norwich Research Park, \\ Norwich, NR47TJ, UK. \\ * e-mail: edgar.ssilva@ufpe.br
}

Santo-Silva, E.E., Almeida, W.R., Tabarelli, M. and Peres, C.A., 2016. Habitat fragmentation and the future structure of tree assemblages in a fragmented Atlantic forest landscape. Plant Ecology, 217(9), pp.1129-1140. DOI 10.1007/s11258-016-0638-1

\begin{abstract}
The biodiversity value of human-modified landscapes has become a central question in tropical forest conservation biology, yet the degree to which plant populations and communities are restructured in response to environmental change remains unclear. . Here, we examine the density of 141 tree species in a fragmented Atlantic Forest landscape dominated by a long history of sugar-cane production. We document shifts in population density in small forest fragments to infer on the magnitude of fragmentationrelated effects, and ultimately the structure of future tree assemblages. Both tree seedlings and adults were sampled across 39 0.1-ha plots: 19 in small fragments $(<100$ ha) and 20 in mature forest stands within the interior of the largest forest remnant of the study landscape (3500 ha). A total of 5,448 seedlings and adults were recorded, with $>55 \%$ of all tree species exhibiting higher densities in small fragments than in mature forest, particularly pioneers ( $>60 \%$ of all species). Seedlings and adults of these proliferating species differed from species exhibiting population declines in terms of wood density and seed size, respectively. Additionally, pioneers were more abundant than shade-tolerant species, as were hardwood species in the case of seedlings. Tree species showing highest population increases consisted largely of long-lived, lightdemanding canopy species bearing soft or hardwood and small-to-medium sized seeds. Tree assemblage structure also differed in terms of forest habitats with small forest fragments supporting few rare species, whereas the most rapidly proliferating species were much more widespread and abundant in fragments. However $60 \%$ of all adult pioneer species recorded in small fragments were not recorded as seedlings in this habitat type, although both seedling and adult assemblages were dominated by pioneer species. Edge-dominated tree assemblages therefore likely experience long term shifts towards greater dominance of long-lived, pioneer canopy species.
\end{abstract}

Key words: extinction debt, forest fragmentation, pioneer species, population density, seed size, tree assemblages, tropical forest. 


\section{Introduction}

Tropical forests represent the world's most diverse biome, accounting for over half of all terrestrial species in addition to provision of key ecosystems services such as carbon storage and climate regulation. However, mounting human population pressure driven by greater demand for forest commodities and agricultural land is expected to threaten the largest remaining tracts of old-growth forests globally (FAO 2011; Fearnside and Barbosa 2004). In particular, habitat loss and fragmentation are major threat processes to tropical biodiversity driving species extinction at multiple scales (Sala et al. 2000). Accordingly, it has been argued that large tropical forest reserves represent an irreplaceable biodiversity conservation strategy and a core element of any effective conservation initiative aiming to safeguard representative portions of regional biodiversity (Laurance 2005; Peres 2005).

However, large forest remnants are either dwindling or missing in many regions, including biodiversity hotspots and centers of species endemism (Ribeiro et al. 2009). Therefore, human-modified landscapes have attracted increasing interests from conservation biologists, particularly as complementary landscape elements such as biodiversity corridors or biodiversity-friendly matrices (Melo et al. 2013). In this context, recent research efforts have identified: (1) several ecological or functional groups sensitive to human disturbances, most of which referred to as forest-dependent species (Girão et al. 2007; Lopes et al. 2009; Melo et al. 2010; Santos et al. 2008; Tabarelli et al. 2010a), (2) the presence of altered but rather impoverished communities in taxonomic, ecological and phylogenetic terms along edge-affected habitats (SantoSilva et al. 2013; Santos et al. 2010; Santos et al. 2008), (3) landscape and patch metrics correlated with species abundance and patterns of community structure such as habitat connectivity, forest cover and core forest to forest edge ratio (XXX). Population declines, species extinctions, shifts in community structure, and collapse in forest structure proceed rapidly as soon as forest edges are created. Although species losses are expected to reach a relaxation point over time, the ultimate nature/composition of tree assemblages in human-modified landscapes remains an open question (ArroyoRodriguez et al. 2012; Arroyo-Rodriguez et al. 2009; Santos et al. 2010; Santos et al. 2008).

The Brazilian Atlantic Forest biome has a long history of human-disturbances and over $80 \%$ of all forest remnants are smaller than 50 ha (Ribeiro et al. 2009). Tree assemblages inhabiting forest edges and small forest fragments (i.e. edge-affected habitats) have provided key evidence on the potential effects imposed by habitat loss and fragmentation, particularly the establishment of forest edges immersed into openhabitat matrices (see reviews in Tabarelli et al. 2010b and Joly et al. 2014).

Impoverished tree assemblages are dominated by some pioneer species, which tend to proliferate from local to regional scales (Lôbo et al. 2011; Tabarelli et al. 2010a). Proliferation of pioneer and light-demanding species (successional species, sensu Laurance et al. 2006b) parallels population collapses and extirpations of species in several ecological groups belonging to the old-growth flora, such as large-seeded (Santos et al. 2008) and emergent species (Oliveira et al. 2008), and those with specialized floral biology (Girão et al. 2007; Lopes et al. 2009). Collectively, these shifts have been interpreted as a successional trajectory triggered by habitat fragmentation transforming edge-affected habitats into early-successional systems (Tabarelli et al. 2008). However, it remains unclear whether shifts in plant assemblage composition have already reached a saturation point even after centuries of forest conversion. 
Here, we examine the population density of 141 tree species as both seedlings and adults in a fragmented Atlantic Forest landscape with a long history of sugar-cane production. We aim to document shifts in species abundance and the structure of tree assemblages in small forest fragments to project the magnitude of fragmentation-related effects, and ultimately the future of these assemblages. First, we identify which species are either proliferating or declining in numbers based on their abundance ratio (abundance in small forest fragments over their abundance in core areas of a large, mature forest remnant) and examine the ecological composition of these two operational groups of tree species considering both age classes. Second, we examine how relative density trends play out within functional groups related to regeneration strategy, seed size and wood density. Species abundances and species accumulation curves are presented for seedlings and adults in both habitats, with special attention to the top-ten proliferating species. Finally, we discuss the implications of our findings in relation to current knowledge on tree assemblage responses to habitat fragmentation and the conservation value human-modified landscapes.

\section{Methods}

Study area

This study was carried out in a severely fragmented landscape of the Brazilian northeastern Atlantic Forest, located within the 66,700-ha Usina Serra Grande landholding ( $8^{\circ} 30^{\prime} \mathrm{S}, 35^{\circ} 50^{\prime} \mathrm{W}$; Fig. 1). The area is comprised largely of sugarcane monoculture surrounding 109 forest fragments ranging in size between 1.6 and 3,500 ha.. The region presents a tropical climate, with a mean annual rainfall of $\sim 2,000 \mathrm{~mm}$ and temperatures between $22-24^{\circ} \mathrm{C}$, with a dry season lasting three months (November to January). At a regional scale, the evergreen or semi-deciduous forest remnants (Veloso et al. 1991) are largely dominated by Lauraceae, Sapotaceae, Moraceae and Fabaceae tree species (Grillo et al. 2005).

Serra Grande represents a long-standing fragmented forest landscape, given that sugarcane plantations date back to the $19^{\text {th }}$ century (Santos et al. 2008). In addition, the size and shape of forest fragments have remained stable for over two centuries to ensure a stable water supply for sugarcane irrigation. The Serra Grande landscape also holds the 3,500-ha Coimbra Forest, the largest forest remnant in the region, which still retains large areas of pristine forest and a flora and fauna typical of undisturbed primary forest (Oliveira et al. 2004; Santos et al. 2008). As in previous studies (Girão et al. 2007; Lopes et al. 2009; Santo-Silva et al. 2013; Santos et al. 2008; Tabarelli et al. 2010a), we therefore used Coimbra as a mature forest control area.

\section{Seedling and adult tree surveys}

Surveys of adult and seedling trees were carried out only in the dry seasons. Tree assemblages were sampled at 39 plots of 0.1 ha $(10 \times 100 \mathrm{~m})$ within two habitat types: (1) mature forest -20 plots in old-growth forest stands located inside the Coimbra Forest and at least $200 \mathrm{~m}$ from the nearest edge; and (2) small forest fragments - 19 plots in 19 forest fragments (one plot placed at the geometric center of each fragment) ranging in size from 3.4 to 91.2 ha (mean $=40.9$ ha; median $=31.7$ ha). This set of forest fragments was selected because remaining Atlantic forest patches are vastly dominated by patches smaller than 100 ha (Ribeiro et al. 2009). Surveys of adult stems were restricted to trees larger than $10 \mathrm{~cm}$ in $\mathrm{DBH}$ [diameter at breast height]. During seedling surveys, we randomly selected 100 seedlings $10-50 \mathrm{~cm}$ in total height per 0.1 ha plot. In particular, we set 200 random points within each plot and sampled the nearest seedling to each point. We subsequently discarded all seedlings that did not 
belong to any of the tree species based on stems $>10 \mathrm{~cm} \mathrm{DBH}$, and then randomly selected a subset of 100 seedlings. We decided to use this methodology to avoid sampling monospecific seedling aggregations and to ensure an equal sample size across all sites. These overlapping adult and seedling tree assemblages have yet to be examined together, but previous studies have considered them separately [Santos et al. (2008) and Santo-Silva et al. (2013), respectively]. The spatial distribution of plots is necessarily limited because all mature forest areas are restricted to the same large fragment (Coimbra Forest). However, the overall distribution of the tree flora in the Serra Grande landscape is not affected by large-scale spatial effects (Santos et al. 2008).

\section{Regeneration niche, seed size, and wood density}

To identify likely ecological attributes driving changes in population density, we assigned each species into functional groups according their regeneration niche, seed size, and wood density, which is a good correlate of individual growth rate (REF). In terms of regeneration niche, all stems were assigned into either (1) pioneer or (2) shadetolerant species (Hartshorn 1978). For seed size, species were assigned into four groups: (1) small (<6 mm in length), (2) medium-sized (6-15 mm), (3) large ( $>15-30 \mathrm{~mm})$, and (4) very large (> $30 \mathrm{~mm}$ ). For wood density, we assigned each species into two major groups: (1) softwood (wood density $<0.7 \mathrm{~g} / \mathrm{cm}^{3}$ ) or (2) hardwood $\left(>0.7 \mathrm{~g} / \mathrm{cm}^{3}\right)$. These criteria for assigning species into functional groupings had been adopted previously (Michalski et al. 2007; Oliveira et al. 2004; Santo-Silva et al. 2013; Santos et al. 2008). Information on regeneration niche and seed size were obtained from a comprehensive literature review, including floras and checklists (e.g., Lorenzi 1992; Oliveira 2007; van Roosmalen 1985), and complemented by our own personal knowledge following over two decades of research on Atlantic Forest tree species (e.g., Melo et al. 2006; Oliveira et al. 2004; Santo-Silva et al. 2013; Silva and Tabarelli 2000; Tabarelli et al. 1999; Tabarelli and Peres 2002). Data of wood density were obtained from Zanne et al. (2009), and we used average values for genera or families if speciesspecific data were unavailable.

\section{Data analysis}

For each ontogenetic stage (seedlings and adults) and habitat type (small fragments and the 3,500-ha patch of mature forest), we calculated the average population density of each species (i.e. total abundance/number of 0.1 ha plots). To infer on either positive or negative changes in population densities in small fragments, we calculated separately for adults and seedlings the ratio between the density in small fragments and the density in mature forest for each species (hereafter, $S F / M F$ ratio). SF/MF ratios $>1$ or $<1$ indicate species that were either more abundant or less abundant in small fragments than in mature forest areas, respectively. Because some species were only found in either small fragments or mature forest, we arbitrarily added a singleton of those species to the habitat type where they were apparently missing in order to enable estimates of the $\mathrm{SF} / \mathrm{MF}$ ratio.

Using only those species that had been assigned into a functional group in terms of regeneration niche, seed size, and wood density, we first performed chi-square tests to evaluate the overall proportions of these groupings in relation to the SF/MF ratio. . Second, we performed GLMs (Generalized Linear Models) adopting the regeneration niche, seed size, and wood density as factors and the 1 -transformed SF/MF ratio as a response variable. Chi-square tests and GLMs were performed separately for adults and seedlings. Finally, we provide species-rank curves on the basis of both species abundance and distribution (number of plots) for each habitat (Magurran 1988), 
considering both adult and seedling assemblages. All analyses were performed in Statistica 7 and in R (R-Core-Team 2012).

\section{Results}

A total of 2,640 seedlings representing 76 tree species were recorded across both in the Coimbra Forest and small fragments, with 48 species (63.2\%) exhibiting higher abundances in small fragments ( $\mathrm{SF} / \mathrm{MF}$ ratios > 1). Most of these proliferating species had been classed as pioneers $(72.9 \%)$, hard-wooded $(54.2 \%)$, and bearing either medium-sized $(50 \%)$ or small seeds $(27.1 \%)$. None of the species with a SF/MF ratios > 1 were large-seeded. Furthermore, proliferating and declining species in seedling assemblages differed in terms of functional composition, particularly in terms of woody density: the percentage of softwood species was one third lower in proliferating species $\left(\chi^{2}=6.12\right.$, df $=1, P=0.013$; Fig. 2C), whereas there were no differences in terms of regeneration niche $\left(\chi^{2}=1.21, \mathrm{df}=1, P=0.27\right.$; Fig. $\left.2 \mathrm{~A}\right)$ and seed size $\left(\chi^{2}=5.76, \mathrm{df}=\right.$ $3, P=0.124$; Fig. 2B).

Considering adults, we recorded a total of 2,778 trees representing 103 species, 58 $(56.3 \%)$ of which were assigned to proliferating species. Consistent with the pattern recorded for seedlings, this group consisted predominantly of pioneers $(62.1 \%)$ and softwood species $(70.7 \%)$ bearing medium-sized (60.3\%) and small seeds $(24.1 \%)$. There were no differences between proliferating and declining species in relation to regeneration niche $\left(\chi^{2}=0.19, \mathrm{df}=1, P=0.659\right.$; Fig. $\left.2 \mathrm{D}\right)$ and wood density $\left(\chi^{2}=1.29\right.$, $\mathrm{df}=1, P=0.256$; Fig. $2 \mathrm{~F})$. However, large and very large-seeded adult trees were more frequent among declining species than those that were proliferating $\left(\chi^{2}=8.23, \mathrm{df}=3, P\right.$ $=0.041$; Fig. 2E).

The relative density of different species in terms of their SF/MF ratios was highly variable ranging from 0.004 to 81.1 in seedling assemblages and from 0.003 to 77.9 in adult assemblages. Among all functional groups, pioneers were more abundant than shade-tolerant species (Adults, $F=4.82, P=0.031$; Seedlings, $F=5.21, P=0.025$; Fig. $3 \mathrm{~A}$ and $3 \mathrm{~B})$, whereas hardwood species were more abundant than softwood species in seedlings $(F=10.44, P=0.002)$. Although pioneer species on average exhibited higher relative densities than shade-tolerant species in both ontogenetic stages, this elevated density was more pronounced in seedlings than in adults (Fig. 3C and D). When we compared population densities between adult and seedling assemblages, almost all shade-tolerant species exhibited lower densities at the seedling stage (Fig. 4A), whereas pioneer species were much more evenly split between those exhibiting either lower or greater densities at the seedling stage (Fig. 4B). Considering both adult and seedling assemblages, hyperdominant species in small fragments exhibiting the highest relative abundance ratios were predominantly long-lived, canopy-gap demanding species bearing small-to-medium sized seeds (Table 1).

Finally, adult and seedling assemblages differed markedly in terms of community structure across habitat types since only a small number of rare seedling species were recorded in small fragments (Fig. 5), whereby the number of species represented by only one or two individuals in small fragment plots was $81 \%$ lower compared to those in mature forest areas. Among the top-ranking 10 proliferating species (highest SF/MF ratios), only three were recorded as both adults and seedlings in the Coimbra Forest, where they were typically rare. In contrast, most of these top-ten species were very abundant in small fragments as both seedling and adults, including the pioneers Byrsonima sericea, Bowdichia virgilioides, Cupania oblongifolia and Cupania racemosa (see Table 1). A similar pattern was observed considering species abundances 
across plots (Fig. 6). Compared to the Coimbra Forest, seedling assemblages in small forest fragments exhibited a reduction of two thirds or more in the number of species recorded in only one or two plots. Additionally, the three top-ten species in mature forest patches were only recorded in three plots. In small fragments, however, the topten species were relatively ubiquitous, occurring as adults in 2-17 plots and as seedlings in 2-18 plots. Bowdichia virgilioides was the most frequent species in adult assemblages (17 plots), while Cupania oblongifolia was the most frequent in seedling assemblages (18 plots). Despite the high relative abundance and occupancy exhibited by some pioneer species and a marked reduction in rare species, over $60 \%$ of all pioneer species recorded as adults in small fragments failed to be recorded as seedlings in this habitat type, even if both adult and seedling assemblages were dominated by pioneers.

\section{Discussion}

Tropical forest dynamics cannot be properly addressed without long-term demographic surveys, but for obvious reasons this approach is rarely feasible. We adopted simple measures of population density in seedling and adult tree assemblages to infer on the nature of future floristic transitions and the magnitude of fragmentation-related effects. Our results suggest that a large proportion of tree species are still experiencing altered abundances as seedlings and adults in small forest fragments, even two centuries after primary forest fragmentation and patch isolation. Several tree species are apparently declining while others are proliferating in small forest fragments. Both negative and positive shifts in abundance, rather than occurring randomly, were observed in particular tree functional groups related to ther regeneration strategy, seed size and wood density. In general, shade-tolerant and heavy-wooded representatives of the oldgrowth flora have declined, while pioneers could respond in both directions. However, most top-ranking species that proliferated as seedlings included both hard and softwood pioneers, and long-lived species inhabiting the forest canopy, which were dominant as both seedlings and adults in XXXXX. Several proliferating taxa that are becoming hyperabundant in small forest fragments were rare in core forest interior areas of the Coimbra forest, suggesting a release in abundance in edge-dominated forest habitats. These differential responses across several trait-based functional groups largely result in severely altered plant assemblages in small fragments, which are becoming impoverished in both taxonomic and functional terms. Finally, if we accept taxonomic and ecological differences between seedling and adult assemblages in small fragments as a prognosis of future floristic transitions, the future adult tree flora of the ancient Serra Grande forest landscape will likely be radically different from the one today.

Our findings reinforce key notions about fragmentation-related effects on tropical tree species assemblages, several of which supported by empirical evidence from Amazonian and other Atlantic forests. In particular (1) population declines and local extinctions in human-modified landscapes predominantly affect particular functional groups (XXXX), (2) edge-affected habitats tend to support distorted tree species assemblages in both taxonomic and functional terms (Laurance et al. 2006a; Laurance et al. 2006b; Tabarelli et al. 2008), (3) these distortions can be readily observed in seedling assemblages (Santo-Silva et al. 2013); (3) small forest fragments are becoming increasingly dominated by pioneer species (cf. Pütz et al. 2011; Tabarelli et al. 2008), (4) some native pioneer species are proliferating at multiple spatial scales (Tabarelli et al. 2012), particularly Byrsonima sericea, Bowdichia virgilioides, Cupania oblongifolia and Cupania racemosa. Although it has been shown that tree assemblages in small forest fragments are predominantly comprised of small-seeded species (Melo et al. 2010; Santo-Silva et al. 2013; Santos et al. 2008), our results suggest that production of 
large numbers of small seeds in itself does not necessarily confer the ability to proliferate in small fragments.

Finally, we offer new evidence for the establishment of adult tree assemblages dominated by a mix of short- and long-lived successional canopy species that are lightdemanding pioneers, which represent only a small fraction of the pioneer flora at any tropical forest $(\mathrm{XXX})$. This more detailed description of the floristic drift experienced by edge-affected habitats support other key working hypotheses: (1) assemblage-wide compositional shifts tend to persist for however long forest environments remain exposed to the open-habitat matrix, suggesting that thse shifts are more permanent rather than transitory; and (2) edge-dominated forest habitats approach typical conditions of early successional systems, even without any history of anthropogenic disturbance, including clear-cuts and logging (Tabarelli et al. 2008).

Although we did not explicitly exam causal mechanisms for the patterns we uncovered in this study, they have been generally considered to be caused by edge effects and dispersal failure. In particular, mechanistic explanations on nonrandom compositional drift are likely related to reduced dispersal movement of large seeds at multiple spatial scales (Cramer et al. 2007; Melo et al. 2006; Melo et al. 2010; Peres and Palacios 2007; Silva and Tabarelli 2000), persistently low seedling recruitment of shade-tolerant old-growth tree species (Santo-Silva et al. 2013), increased mortality of large trees due to uprooting and physiological stress (Laurance et al. 2000), and hyperproliferation of light-demanding species facilitated by high propagule pressure and increased light availability (Tabarelli et al. 2008). These mechanisms are likely to account for the prevalence of canopy, rather than emergent, hardwooded pioneer tree species among the ten top-ranking SF/MF ratios, such as those from the genus Cupania.

Tree assemblage response to habitat loss and fragmentation, and particularly forest edge creation, in Amazonian forests are consistent with the patterns described here and in other studies for the Atlantic Forest. For example, the collapse of the old-growth tree flora and the proliferation of pioneers, particularly short-lived species, have been well documented in Amazonian forest landscapes dominated by both cattle pastures and young secondary forests (Laurance et al. 2006b) and open water (Benchimol and Peres 2015). Based on the patterns found here, we also expect that recently fragmented Amazonian forest landscapes will eventually experience a proliferation of long-lived, canopy pioneers, including hardwooded species. In other words, patterns documented for 'old' and 'newly' fragmented landscapes represent different stages of a long continuum of floristic drift experienced by edge-dominated habitats.

On the other hand, these apparently general and widespread patterns are in marked contrast to those documented in other neotropical biotas, such as Lacandona in Mexico, where forest fragments smaller than 100 ha exhibit tree assemblages with species diversity, structure and relative abundance of pioneer similar to those in continuous forest (Hernandez-Ruedas et al. 2014). Given our rationale, this puzzling contrast may result from a different disturbance history and configuration of these Mesoamerican landscapes. Nevertheless, Amazonian the Atlantic forests present analogous responses regardless of landscape configuration, time elapsed since forest fragmentation and isolation, and abundance of large-bodied vertebrate seed dispersers (Laurance et al. 2006a; Laurance et al. 2006b; Santos et al. 2008). We call attention to the evolutionary biogeography of different regions as underlying forces shaping the intensity with which, rather the direction, different tropical forest settings respond to habitat loss fragmentation. With an evolutionary-time exposure to catastrophic natural disturbances events such as hurricanes, plus a long history of human disturbance from preColombian populations, Mexican tropical forest floras "naturally support" a higher 
proportion of disturbance-adapted species (XXREF HERE X), thereby exhibiting less pronounced responses to contemporary conversion to non-forest land uses.

Although marked responses of tree assemblages to habitat fragmentation have already been documented, the floristic and functional trajectories experienced by these assemblages over longer isolation time lags remain poorly understood. Tree assemblages inhabiting edge-affected habitats probably experience long-term shifts in abundance and composition and most forests within recently fragmented landscapes should be referred to as transitional forests as suggested by recent findings in Amazonia (XXX). Such transitional forests move towards assemblages dominated by early to late successional pioneer trees as documented here. In terms of conservation implications, pioneers and light-demanding species represent only a small fraction of tropical forest floras (REF?), although their relative contribution is likely to vary across biotas. This has clear implications to contemporary forest diversity even if only a modest fraction of this ecological group can become hyper-abundant in edge-dominated habitats as advocated here. Pioneer-dominated tree assemblages, including those at Serra Grande, have reduced floristic and functional diversity (Santos et al. 2008), reduced size structure (Oliveira et al. 2008), low levels of carbon retention (Paula et al. 2011), and reduced diversity of floral attributes (Girão et al. 2007; Lopes et al. 2009) and phylogenetic traits (Santos et al. 2010). Moreover, pioneer-dominated assemblages present an altered pattern of fruit phenology and much lower relative abundance of trees bearing large fruits (Tabarelli et al. 2010a), which can reduce habitat quality for many frugivorous vertebrates (sensu lato) that play important roles in forest regeneration as seed dispersers and seed predators. Finally, tropical forest ecosystems experiencing with high levels of recurrent disturbance tend to provide reduced levels of ecosystems services, including carbon retention and water cycling (Melo et al. 2013). This reinforces the notion that landscapes consisting of small fragments far from large tracts of old-growth forest and surrounded by a cropland matrix represent low conservation value (Melo et al. 2013; Tabarelli et al. 2010b). However, exactly what functional traits ensures species persistence in fragmented landscapes such as Serra Grande are still required, as this question is far from completely elucidated. 


\section{REFERENCES}

Arroyo-Rodriguez, V., Cavender-Bares, J., Escobar, F., Melo, F.P.L., Tabarelli, M., Santos, B.A., 2012. Maintenance of tree phylogenetic diversity in a highly fragmented rain forest. Journal of Ecology 100, 702-711.

Arroyo-Rodriguez, V., Pineda, E., Escobar, F., Benitez-Malvido, J., 2009. Value of Small Patches in the Conservation of Plant-Species Diversity in Highly Fragmented Rainforest. Conservation Biology 23, 729-739.

Cramer, J.M., Mesquita, R.C.G., Williamson, G.B., 2007. Forest fragmentation differentially affects seed dispersal of large and small-seeded tropical trees. Biological Conservation 137, 415-423.

FAO, 2011. State of the world's forests 2011. Food and Agriculture Organization of the United Nations, Rome.

Fearnside, P.M., Barbosa, K.I., 2004. Accelerating deforestation in Brazilian Amazonia: towards answering open questions. Environmental Conservation 31, 7-10.

Girão, L.C., Lopes, A.V., Tabarelli, M., Bruna, E.M., 2007. Changes in tree reproductive traits reduce functional diversity in a fragmented Atlantic Forest landscape. Plos One 2, e908.

Grillo, A.S., Oliveira, M.A., Tabarelli, M., 2005. Árvores, In Diversidade biológica e conservação da floresta Atlântica ao norte do rio São Francisco. eds K. Pôrto, J.S. Almeida-Cortez, M. Tabarelli, pp. 191-216. Ministério do Meio Ambiente, Brasília.

Hartshorn, G.S., 1978. Treefalls and tropical forest dynamics, In Tropical trees as living systems. eds P.B. Tomlinson, M.H. Zimmermann, pp. 617-638. Cambridge University Press, New York.

Hernandez-Ruedas, M.A., Arroyo-Rodriguez, V., Meave, J.A., Martinez-Ramos, M., Ibarra-Manriquez, G., Martinez, E., Jamangape, G., Melo, F.P.L., Santos, B.A., 2014. Conserving Tropical Tree Diversity and Forest Structure: The Value of Small Rainforest Patches in Moderately-Managed Landscapes. Plos One 9.

Joly, C.A., Metzger, J.P., Tabarelli, M., 2014. Experiences from the Brazilian Atlantic Forest: ecological findings and conservation initiatives. New Phytologist 204, 459-473.

Laurance, W.F., 2005. When bigger is better: the need for Amazonian mega-reserves. Trends in ecology \& evolution 20, 645-648.

Laurance, W.F., Delamonica, P., Laurance, S.G., Vasconcelos, H.L., Lovejoy, T.E., 2000. Conservation - Rainforest fragmentation kills big trees. Nature 404, 836-836.

Laurance, W.F., Nascimento, H.E.M., Laurance, S.G., Andrade, A., Ribeiro, J.E.L., Giraldo, J.P., Lovejoy, T.E., Condit, R., Chave, J., Harms, K.E., D'Angelo, 
S.A., 2006a. Rapid decay of tree-community composition in Amazonian forest fragments. Proceedings of the National Academy of Sciences 103, 19010-19014.

Laurance, W.F., Nascimento, H.E.M., Laurance, S.G., Andrade, A.C., Fearnside, P.M., Ribeiro, J.E.L., Capretz, R.L., 2006b. Rain forest fragmentation and the proliferation of successional trees. Ecology 87, 469-482.

Lôbo, D., Leão, T., Melo, F.P.L., Santos, A.M.M., Tabarelli, M., 2011. Forest fragmentation drives Atlantic forest of northeastern Brazil to biotic homogenization. Diversity and Distributions 17, 287-296.

Lopes, A.V., Girao, L.C., Santos, B.A., Peres, C.A., Tabarelli, M., 2009. Long-term erosion of tree reproductive trait diversity in edge-dominated Atlantic forest fragments. Biological Conservation 142, 1154-1165.

Lorenzi, H., 1992. Árvores brasileiras. Plantarum, Nova Odessa.

Magurran, A.E., 1988. Ecological diversity and its measurement. Cambridge University Press, Cambridge.

Melo, F.P.L., Arroyo-Rodriguez, V., Fahrig, L., Martinez-Ramos, M., Tabarelli, M., 2013. On the hope for biodiversity-friendly tropical landscapes. Trends in ecology \& evolution 28, 462-468.

Melo, F.P.L., Dirzo, R., Tabarelli, M., 2006. Biased seed rain in forest edges: Evidence from the Brazilian Atlantic forest. Biological Conservation 132, 50-60.

Melo, F.P.L., Martinez-Salas, E., Benitez-Malvido, J., Ceballos, G., 2010. Forest fragmentation reduces recruitment of large-seeded tree species in a semideciduous tropical forest of southern Mexico. Journal of Tropical Ecology $26,35-43$.

Michalski, F., Nishi, I., Peres, C.A., 2007. Disturbance-mediated drift in tree functional groups in Amazonian Forest fragments. Biotropica 39, 691-701.

Oliveira, M.A., 2007. Fragmentação e riqueza de árvores em escala local e regional na floresta Atlântica nordestina: implicações para a conservação, In Departamento de Botânica. Universidade Federal de Pernambuco, Recife.

Oliveira, M.A., Grillo, A.S., Tabarelli, M., 2004. Forest edge in the Brazilian Atlantic forest: drastic changes in tree species assemblages. Oryx 38, 389-394.

Oliveira, M.A., Santos, A.M.M., Tabarelli, M., 2008. Profound impoverishment of the large-tree stand in a hyper-fragmented landscape of the Atlantic forest. Forest Ecology and Management 256, 1910-1917.

Paula, M.D., Alves-Costa, C.P., Tabarelli, M., 2011. Carbon storage in a fragmented landscape of Atlantic forest: the role played by edge-affected habitats and emergent trees. Tropical Conservation Science 4, 349-358. 
Peres, C.A., 2005. Why we need megareserves in Amazonia. Conservation Biology 19, 728-733.

Peres, C.A., Palacios, E., 2007. Basin-wide effects of game harvest on vertebrate population densities in Amazonian forests: Implications for animal-mediated seed dispersal. Biotropica 39, 304-315.

Pütz, S., Groeneveld, J., Alves, L.F., Metzger, J.P., Huth, A., 2011. Fragmentation drives tropical forest fragments to early successional states: A modelling study for Brazilian Atlantic forests. Ecological Modelling 222, 1986-1997.

R-Core-Team, 2012. R: A language and environment for statistical computing. R Foundation for Statistical Computing, Vienna, http://www.R-project.org/.

Ribeiro, M.C., Metzger, J.P., Martensen, A.C., Ponzoni, F.J., Hirota, M.M., 2009. The Brazilian Atlantic Forest: How much is left, and how is the remaining forest distributed? Implications for conservation. Biological Conservation 142, 1141-1153.

Sala, O.E., Chapin, F.S., Armesto, J.J., Berlow, E., Bloomfield, J., Dirzo, R., HuberSanwald, E., Huenneke, L.F., Jackson, R.B., Kinzig, A., Leemans, R., Lodge, D.M., Mooney, H.A., Oesterheld, M., Poff, N.L., Sykes, M.T., Walker, B.H., Walker, M., Wall, D.H., 2000. Biodiversity - Global biodiversity scenarios for the year 2100. Science $287,1770-1774$.

Santo-Silva, E.E., Almeida, W.R., Melo, F.P.L., Zickel, C.S., Tabarelli, M., 2013. The nature of seedling assemblages in a fragmented tropical landscape: implications for forest regeneration. Biotropica 45, 386-394.

Santos, B.A., Arroyo-Rodriguez, V., Moreno, C.E., Tabarelli, M., 2010. Edge-Related Loss of Tree Phylogenetic Diversity in the Severely Fragmented Brazilian Atlantic Forest. Plos One 5.

Santos, B.A., Peres, C.A., Oliveira, M.A., Grillo, A., Alves-Costa, C.P., Tabarelli, M., 2008. Drastic erosion in functional attributes of tree assemblages in Atlantic forest fragments of northeastern Brazil. Biological Conservation 141, 249260.

Silva, J.M.C., Tabarelli, M., 2000. Tree species impoverishment and the future flora of the Atlantic forest of northeast Brazil. Nature 404, 72-74.

Tabarelli, M., Aguiar, A.V., Girao, L.C., Peres, C.A., Lopes, A.V., 2010a. Effects of Pioneer Tree Species Hyperabundance on Forest Fragments in Northeastern Brazil. Conservation Biology 24, 1654-1663.

Tabarelli, M., Aguiar, A.V., Ribeiro, M.C., Metzger, J.P., Peres, C.A., 2010b. Prospects for biodiversity conservation in the Atlantic Forest: lessons from aging human-modified landscapes. Biological Conservation 143, 2328-2340.

Tabarelli, M., Lopes, A.V., Peres, C.A., 2008. Edge-effects drive tropical forest fragments towards an early-successional system. Biotropica 40, 657-661. 
Tabarelli, M., Mantovani, W., Peres, C.A., 1999. Effects of habitat fragmentation on plant guild structure in the montane Atlantic forest of southeastern Brazil. Biological Conservation 91, 119-127.

Tabarelli, M., Peres, C.A., 2002. Abiotic and vertebrate seed dispersal in the Brazilian Atlantic forest: implications for forest regeneration. Biological Conservation 106, 165-176.

Tabarelli, M., Peres, C.A., Melo, F.P.L., 2012. The 'few winners and many losers' paradigm revisited: Emerging prospects for tropical forest biodiversity. Biological Conservation 155, 136-140.

van Roosmalen, M.G.M., 1985. Fruits of the Guianan flora. Institute of Systematic Botany, Utrecht.

Veloso, H.P., Rangel-Filho, A.L.R., Lima, J.C.A., 1991. Classificação da vegetação brasileira adaptada a um sistema universal. IBGE, Rio de Janeiro.

Zanne, A.E., Lopez-Gonzalez, G., Coomes, D.A., Jansen, S., Lewis, S.L., Miller, R.B., Swenson, N.G., Wiemann, M.C., Chave, J., 2009. Global woody density database. http://hdl.handle.net/10255/dryad.235. 


\section{TABLE}

Table 1. The ten top-ranking proliferating tree species in small forest fragments at the Serra Grande landscape, northeast Brazil, considering both adult and seedling stages. SF:MF ratios are defined as the density of a given species in small fragments over the density of the same species in a representative large area of mature primary forest. Species classified into short- and long-lived pioneers have a life span shorter and longer than 25 years, respectively.

\begin{tabular}{|c|c|c|c|c|c|c|c|}
\hline Species & Family & $\begin{array}{l}\text { Regeneration } \\
\text { niche }\end{array}$ & Life span & Seed size & $\begin{array}{l}\text { Wood } \\
\text { density }\end{array}$ & $\begin{array}{c}\text { Forest } \\
\text { stratification }\end{array}$ & $\begin{array}{l}\text { SF:MF } \\
\text { ratio }\end{array}$ \\
\hline \multicolumn{8}{|l|}{ Adults } \\
\hline Bowdichia virgilioides & Fabaceae & pioneer & Long & medium & hard & canopy & 77.9 \\
\hline Byrsonima sericea & Malpighiaceae & pioneer & Short & medium & hard & canopy & 34.7 \\
\hline Cupania revoluta & Sapindaceae & pioneer & long & medium & soft & canopy & 34.7 \\
\hline Artocarpus heterophyllus & Moraceae & pioneer & long & very large & soft & canopy & 21.1 \\
\hline Miconia prasina & Melastomataceae & pioneer & Short & small & hard & canopy & 18.9 \\
\hline Cupania racemosa & Sapindaceae & pioneer & Long & medium & soft & canopy & 18.4 \\
\hline Cupania sp. 2 & Sapindaceae & pioneer & Long & medium & soft & canopy & 15.8 \\
\hline Cupania sp. & Sapindaceae & pioneer & Long & medium & soft & canopy & 15.3 \\
\hline Swartzia macrostachya & Fabaceae & shade-tolerant & Long & medium & hard & canopy & 14.7 \\
\hline Cupania oblongifolia & Sapindaceae & pioneer & Long & medium & soft & canopy & 10.5 \\
\hline \multicolumn{8}{|l|}{ Seedlings } \\
\hline Cupania oblongifolia & Sapindaceae & pioneer & Long & medium & soft & canopy & 81.1 \\
\hline Guazuma ulmifolia & Malvaceae & pioneer & Short & small & soft & canopy & 40 \\
\hline Eugenia sp. 3 & Myrtaceae & pioneer & Short & medium & hard & canopy & 25.3 \\
\hline Artocarpus heterophyllus & Moraceae & pioneer & Long & very large & soft & canopy & 22.1 \\
\hline Alseis floribunda & Rubiaceae & pioneer & Short & small & hard & canopy & 15.8 \\
\hline Cupania racemosa & Sapindaceae & pioneer & Long & medium & soft & canopy & 13.2 \\
\hline Eugenia sp. 4 & Myrtaceae & pioneer & Short & medium & hard & canopy & 12.6 \\
\hline
\end{tabular}




\begin{tabular}{lccccccc} 
Guapira opposita & Nyctaginaceae & pioneer & Long & medium & hard & canopy & 12.6 \\
Brosimum guianense & Moraceae & pioneer & Long & medium & hard & canopy & 10.5 \\
Eschweileria sp. 2 & Araliaceae & shade-tolerant & Long & large & hard & canopy & 8.4 \\
\hline
\end{tabular}




\section{FIGURE LEGENDS}

Fig. 1. Map of the Serra Grande landscape and the distribution of forest fragments investigated.

Fig. 2. Percentage of species assigned into functional groups in terms of regeneration niche, seed size, and wood density at the Serra Grande fragmented landscape. A, B, and $\mathrm{C}$ indicate the percentages of species in seedling assemblages, whereas $\mathrm{D}, \mathrm{E}$, and $\mathrm{F}$ indicate the percentages of species in adult assemblages. Open bars represent the percentage of species with SF:MF ratios $<1$, whereas black bars represent those with a $\mathrm{SF} / \mathrm{MF}>1 . \mathrm{Pio}=$ pioneer; $\mathrm{ST}=$ shade tolerant.

Fig. 3. Relationship between SF/MF ratios and the regeneration niche of (A) adultsand (B) seedlings. Boxes indicate the 25 th and 75 th percentiles, error bars represent the 10 th and 90th percentiles, and the points are the outliers. Solid and dashed lines indicate the median and mean, respectively. Lower panels show the relationship between population densities at the Coimbra Forest and small forest fragments for (C) adult trees and (D) seedlings. Note that the $x$ and $y$ axes share the same scale, so that points above the dashed diagonal line represent species with higher densities in small fragments. SF = small fragments; $\mathrm{MF}=$ mature forest.

Fig. 4. Relationship between changes in population density of adult and seedling trees for (A) shade-tolerant and (B) pioneer species, indicated by black arrows Each arrow represents migration vectors in abundance space for a single species. Arrows moving to either the lower right-hand triangle or upper left-hand triangle represent species more abundant as adults and seedlings, respectively. . Species found only as adults (where recorded densities of seedlings were zero) are represented by grey arrows.

Fig 5. Rank-abundance curves for different tree species based on the relative abundance of adults (A and B) and seedlings (C and D) at the Serra Grande landscape. A and C represent stands within the Coimbra primary forest, whereas B and D represent small forest fragments. Key to the top-ten proliferating species (i.e. highest SF:MF ratios) for each ontogenetic stage as follows: alfl, Alseis floribunda; arhe, Artocarpus heterophyllus; bovi, Bowdichia virgilioides; brgu, Brosimum guianense; byse, Byrsonima sericea; cuob, Cupania oblongifolia; cura, Cupania racemosa; cure, Cupania revoluta; cusp, Cupania sp.; cusp2, Cupania sp. 2; essp2, Eschweileria sp. 2; eusp3, Eugenia sp. 3; eusp4, Eugenia sp. 4; guop, Guapira opposita; guul, Guazuma ulmifolia; mipr, Miconia prasina; swma, Swartzia macrostachya.

Fig 6. Rank-occupancy curves for different tree species based on the number plots where adults (A and B) and seedlings (C and D) were recorded at the Serra Grande landscape. A and $\mathrm{C}$ represent stands within the Coimbra primary forest, whereas B and D represent small forest fragments. Arrows indicate the ten highest SF:MF ratios. Key to the top-ten proliferating species (i.e. highest SF:MF ratios) for each ontogenetic stage as follows: alfl, Alseis floribunda; arhe, Artocarpus heterophyllus; bovi, Bowdichia virgilioides; brgu, Brosimum guianense; byse, Byrsonima sericea; cuob, Cupania oblongifolia; cura, Cupania racemosa; cure, Cupania revoluta; cusp, Cupania sp.; cusp2, Cupania sp. 2; essp2, Eschweileria sp. 2; eusp3, Eugenia sp. 3; eusp4, Eugenia sp. 4; guop, Guapira opposita; guul, Guazuma ulmifolia; mipr, Miconia prasina; swma, Swartzia macrostachya. 


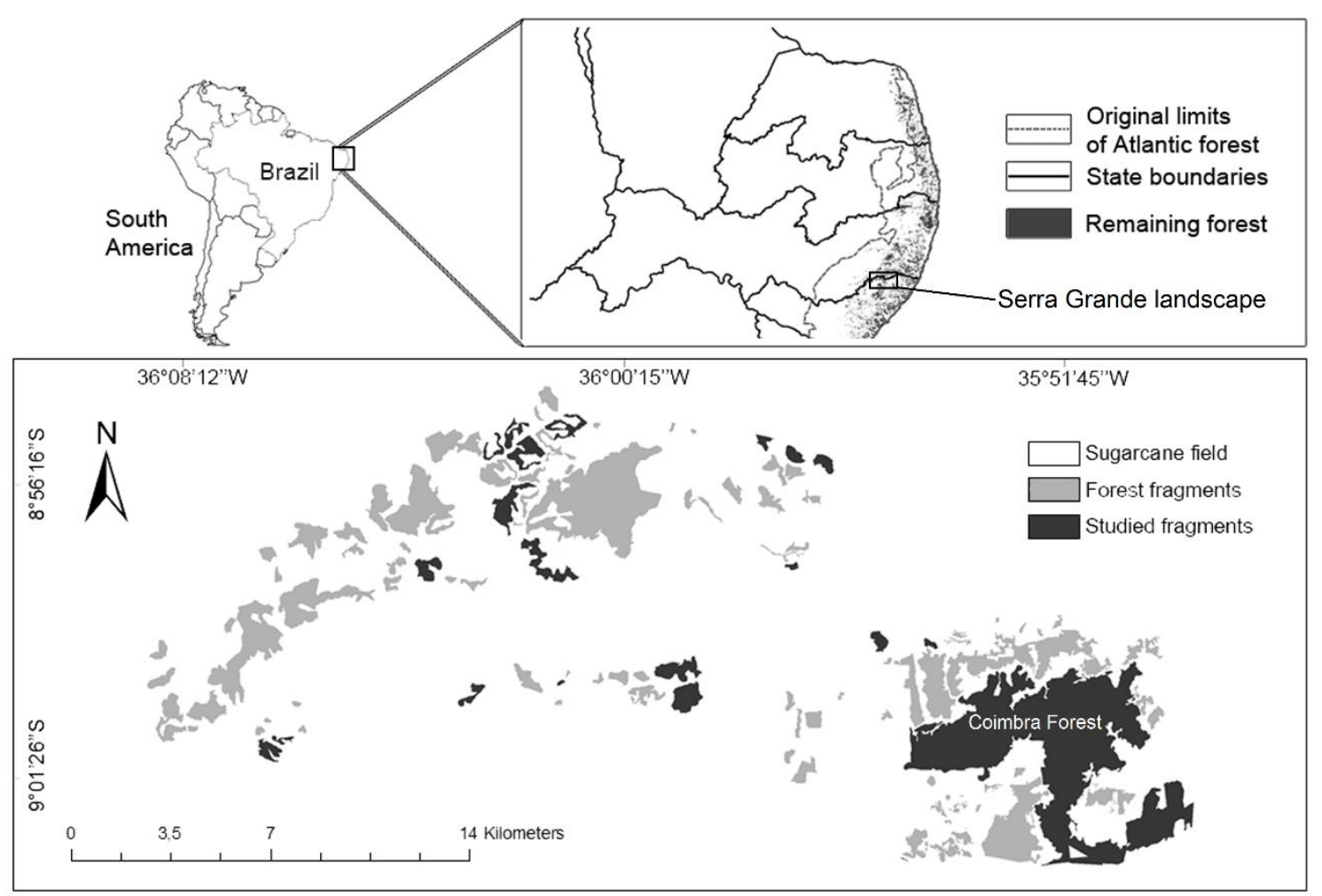

Fig. 1. 
Ratio SF/MF < 1

Ratio SF/MF > 1

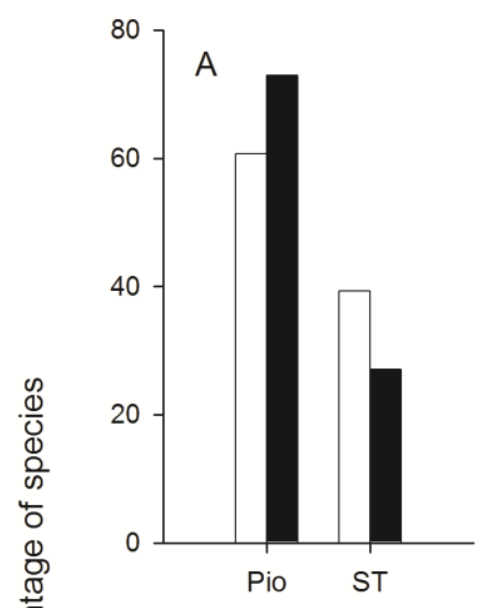

B
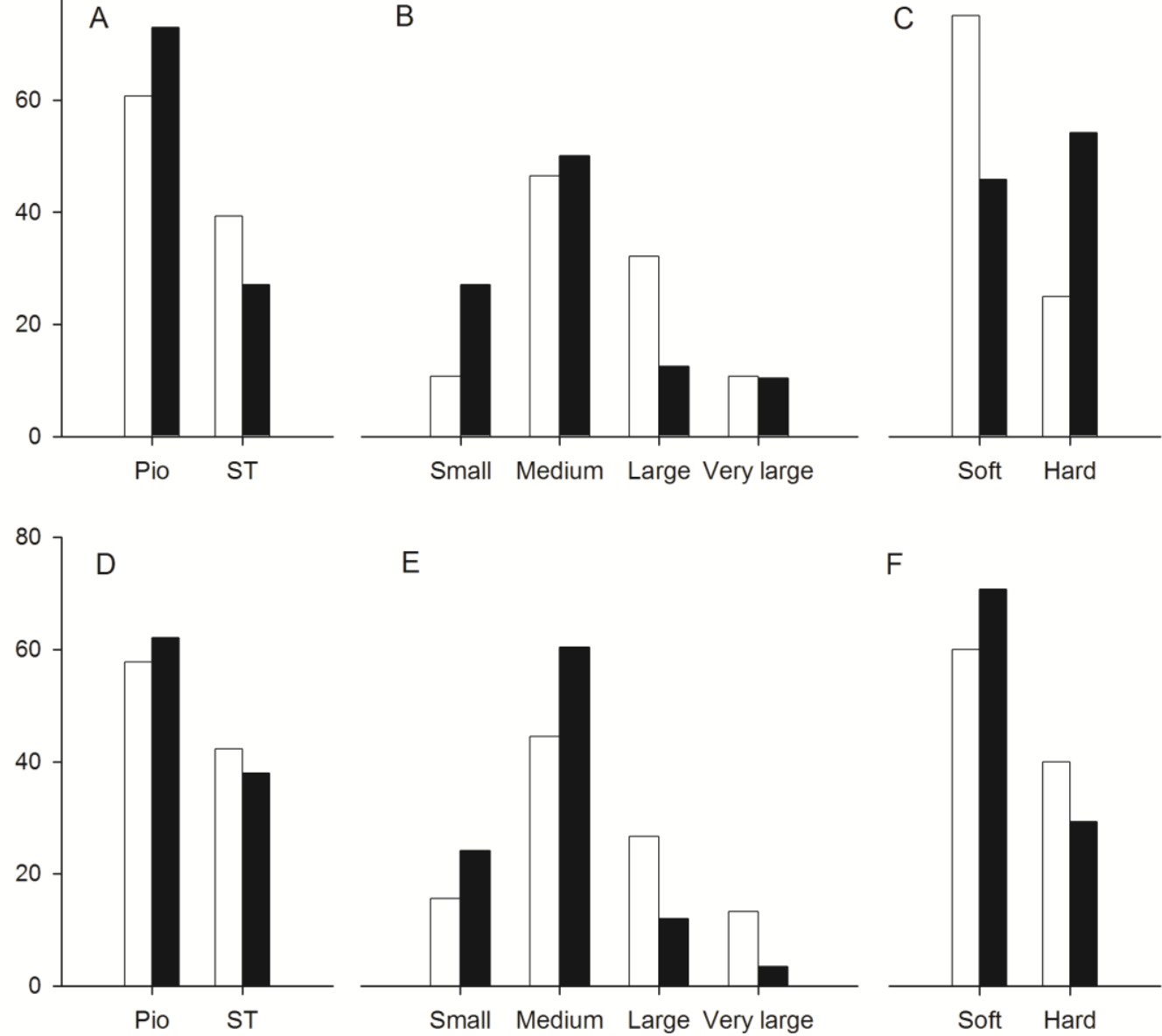

E

F
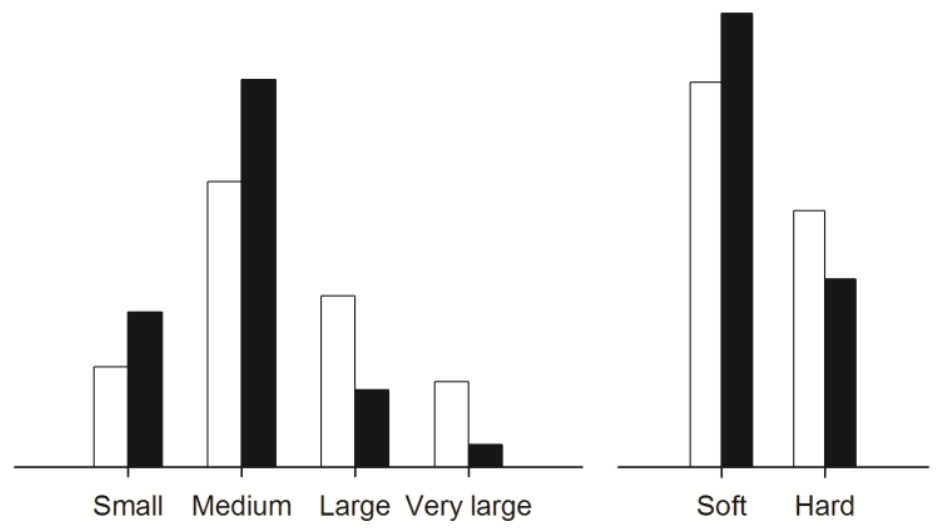

Regeneration niche

Seed size class

Wood density

Fig. 2 

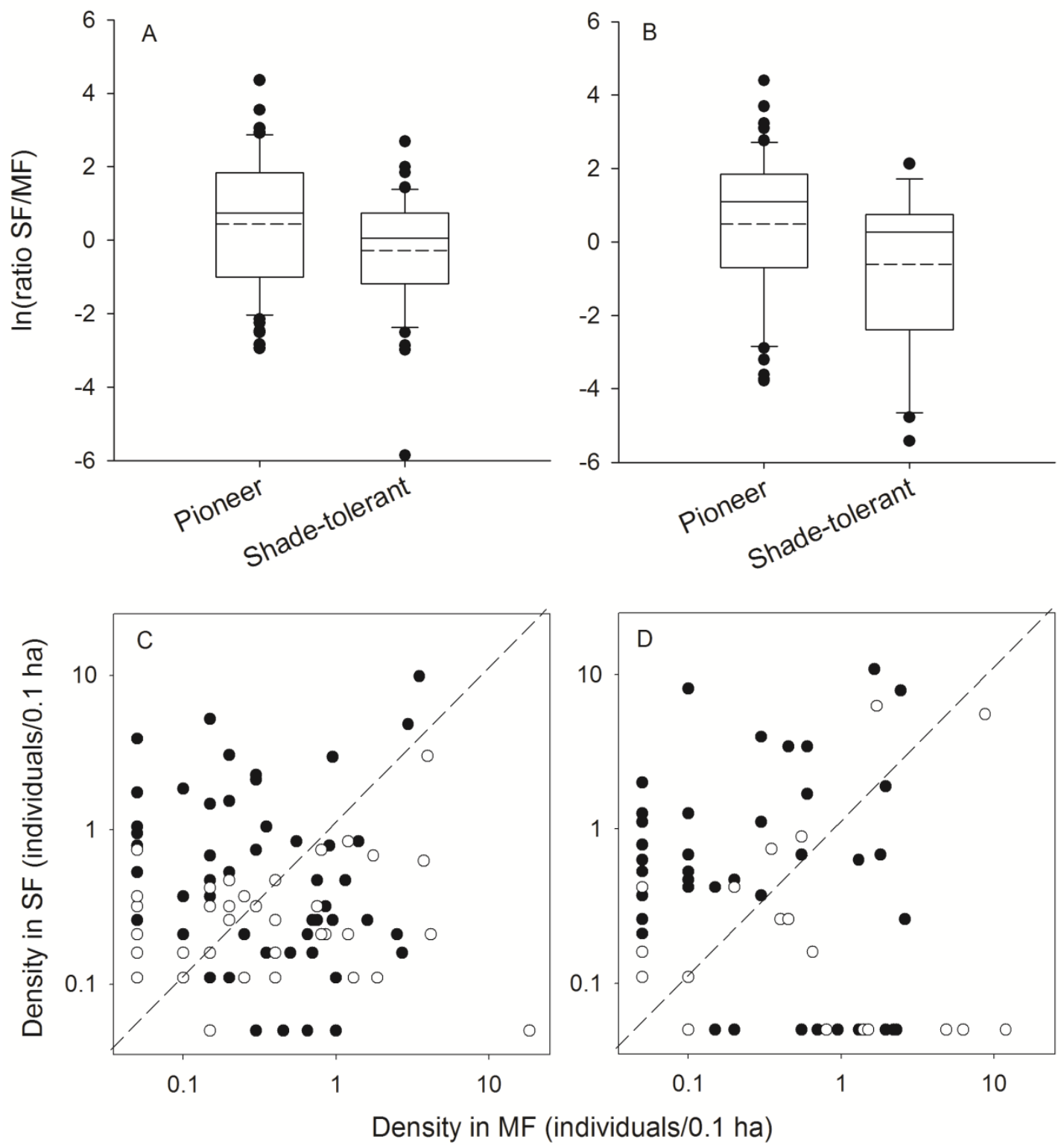

Fig. 3. 

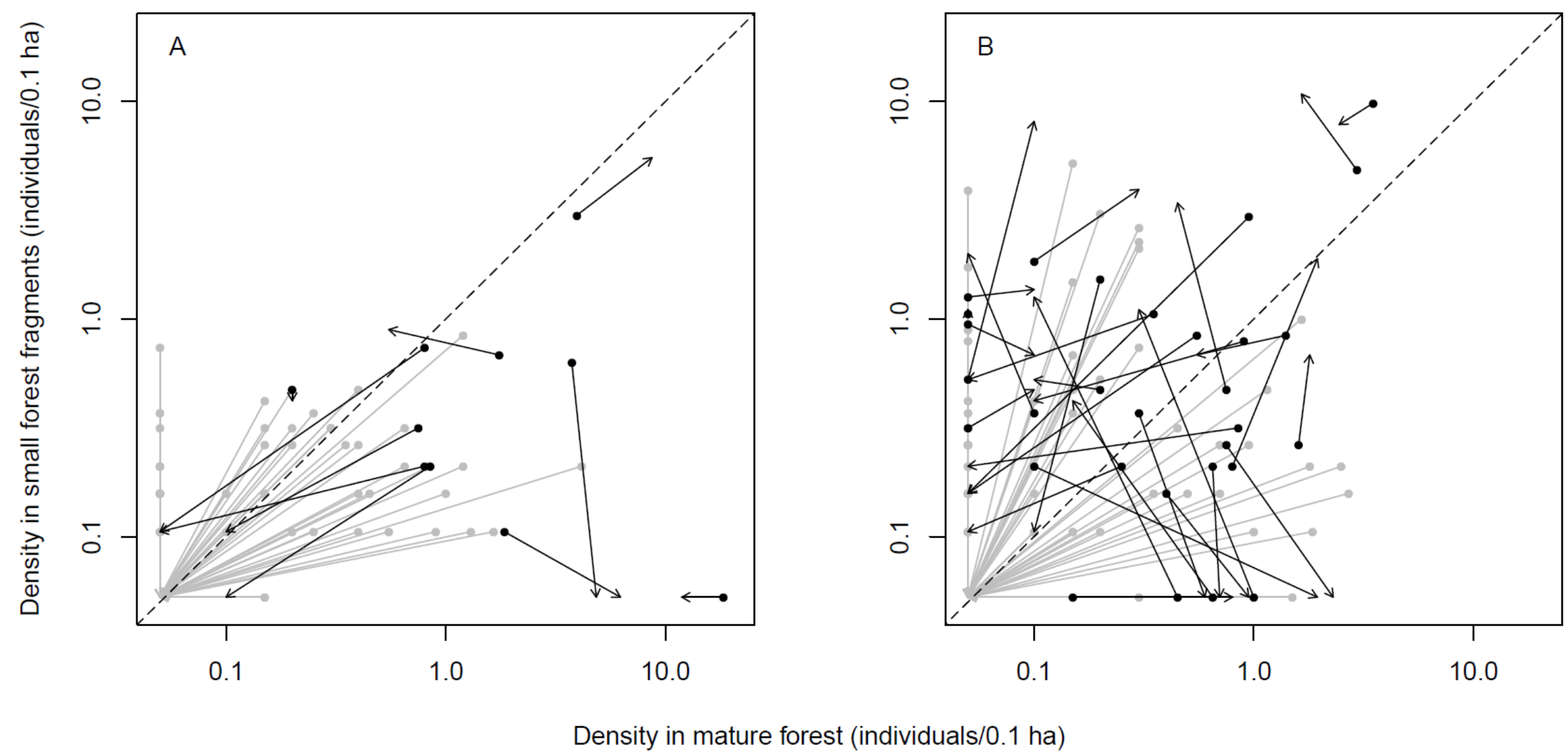

Fig. 4. 

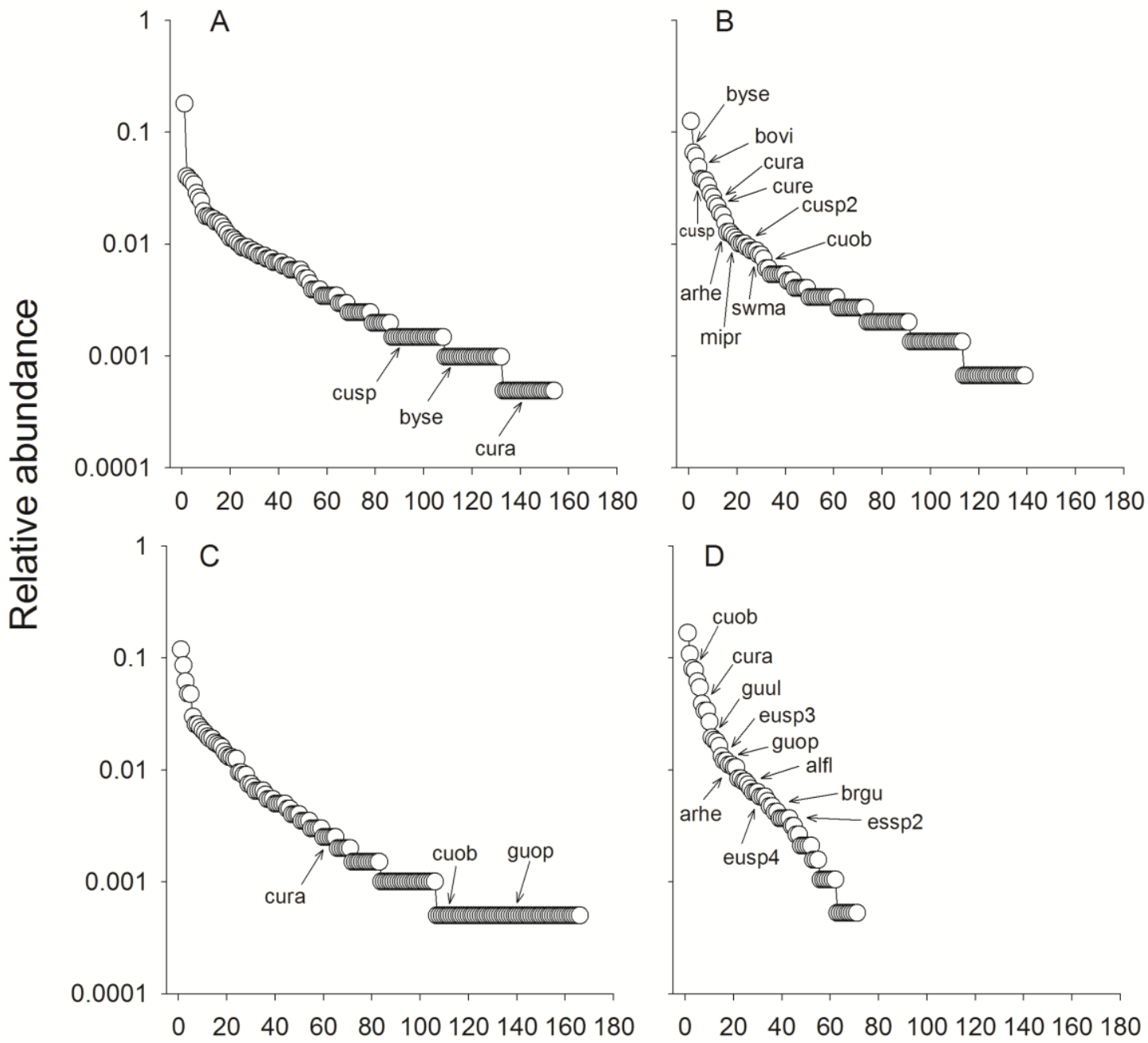

Fig. 5.

Species rank 


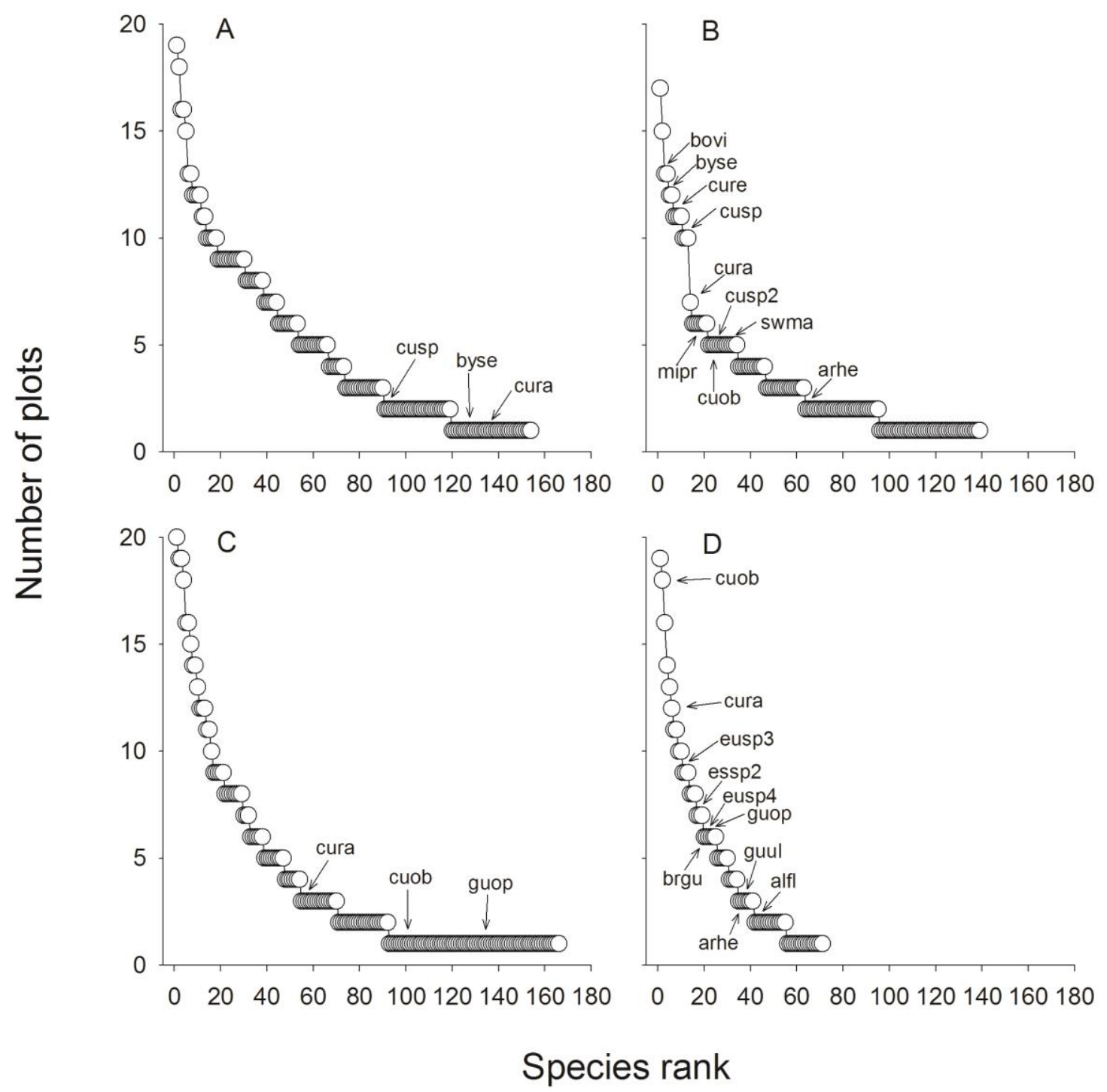

Fig. 6 